Article

\title{
In situ Synchrotron X-ray Thermodiffraction of Boranes
}

\author{
Pascal G. Yot ${ }^{1}$, Philippe Miele ${ }^{2}$ and Umit B. Demirci ${ }^{2, *}$ \\ 1 Institut Charles Gerhardt Montpellier (ICGM), UMR 5253 (UM-CNRS-ENSCM), Universite de Montpellier, \\ CC 15005, Place Eugene Bataillon, 34095 Montpellier cedex 05, France; pascal.yot@umontpellier.fr \\ 2 Institut Europeen des Membranes (IEM), UMR 5635 (CNRS, ENSCM), Universite de Montpellier, \\ Place Eugene Bataillon, CC047, F-34095, Montpellier, France; philippe.miele@umontpellier.fr \\ * Correspondence: umit.demirci@umontpellier.fr; Tel.: +33-467-149-160; Fax: +33-467-149-119 \\ Academic Editor: Helmut Cölfen \\ Received: 19 December 2015; Accepted: 21 January 2016; Published: 25 January 2016
}

\begin{abstract}
Boranes of low molecular weight are crystalline materials that have been much investigated over the past decade in the field of chemical hydrogen storage. In the present work, six of them have been selected to be studied by in situ synchrotron $\mathrm{X}$-ray thermodiffraction. The selected boranes are ammonia borane $\mathrm{NH}_{3} \mathrm{BH}_{3}(\mathrm{AB})$, hydrazine borane $\mathrm{N}_{2} \mathrm{H}_{4} \mathrm{BH}_{3}(\mathrm{HB})$, hydrazine bisborane $\mathrm{N}_{2} \mathrm{H}_{4}\left(\mathrm{BH}_{3}\right)_{2}$ (HBB), lithium $\mathrm{LiN}_{2} \mathrm{H}_{3} \mathrm{BH}_{3}$ (LiHB) and sodium $\mathrm{NaN}_{2} \mathrm{H}_{3} \mathrm{BH}_{3}(\mathrm{NaHB})$ hydrazinidoboranes, and sodium triborane $\mathrm{NaB}_{3} \mathrm{H}_{8}$ (STB). They are first investigated separately over a wide range of temperature (80-300 K), and subsequently compared. Differences in crystal structures, the existence of phase transition, evolutions of unit cell parameters and volumes, and variation of coefficients of thermal expansion can be observed. With respect to $\mathrm{AB}, \mathrm{HB}$ and $\mathrm{HBB}$, the differences are mainly explained in terms of molecule size, conformation and motion (degree of freedom) of the chemical groups $\left(\mathrm{NH}_{3}, \mathrm{~N}_{2} \mathrm{H}_{4}, \mathrm{BH}_{3}\right)$. With respect to $\mathrm{LiHB}, \mathrm{NaHB}$ and $\mathrm{STB}$, the differences are explained by a stabilization effect favored by the alkali cations via $\mathrm{M} \cdots \mathrm{H}$ interactions with four to five borane anions. The main results are presented and discussed herein.
\end{abstract}

Keywords: ammonia borane; hydrazine borane; hydrazine bisborane; hydrazinidoboranes; sodium triborane; synchrotron radiation X-ray powder thermodiffraction

\section{Introduction}

Chemical hydrides and especially boron- and/or nitrogen-based materials have shown to be potential solid-state hydrogen storage materials owing to high gravimetric hydrogen storage capacities [1]. Borohydrides $\mathrm{M}\left(\mathrm{BH}_{4}\right)_{n}$ (with $\mathrm{M}$ as an alkali, alkaline-earth or metal element and $n=1,2,3$ or 4) and borane complexes $\mathrm{L}^{-\mathrm{BH}_{3}}$ (with $\mathrm{L}$ as $\mathrm{NH}_{3}$ or $\mathrm{N}_{2} \mathrm{H}_{4}$ ) are typical candidates [2-4]. For example, the compounds lithium borohydride $\mathrm{LiBH}_{4}$, ammonia borane $\mathrm{NH}_{3} \mathrm{BH}_{3}(\mathrm{AB})$ and hydrazine borane $\mathrm{N}_{2} \mathrm{H}_{4} \mathrm{BH}_{3}(\mathrm{HB})$ carry 18.4, 19.5 and $15.4 \mathrm{wt}$. \% $\mathrm{H}$ respectively. These theoretical hydrogen densities are among the highest. Another example is ammonium borohydride $\left[\mathrm{NH}_{4}\right]\left[\mathrm{BH}_{4}\right]$ with $24.6 \mathrm{wt}$. \% $\mathrm{H}$, but it is unstable dehydrogenating to $\mathrm{AB}$ at sub-zero temperatures [5].

Borane complexes $\mathrm{L}-\mathrm{BH}_{3}$ have been known about for $70-80$ years. For instance, $\mathrm{AB}$ was discovered in 1955 [6], $\mathrm{HB}$ in 1961 [7] and hydrazine bisborane $\mathrm{BH}_{3} \mathrm{~N}_{2} \mathrm{H}_{4} \mathrm{BH}_{3}$ (HBB) in 1951 [8]. It is generally considered that $\mathrm{HBB}$ is a derivative of $\mathrm{HB}$, which is itself a derivative of $\mathrm{AB}$. In that sense, they could be seen as being quite similar. $\mathrm{AB}$ has been much investigated since its discovery and is today a well-known material [1]. In contrast, $\mathrm{HB}$ and HBB have received much less attention until recently; indeed, we have initiated a major study aiming at re-visiting the fundamentals of these pristine boranes $[9,10]$. One of the phases of this study was in situ synchrotron X-ray thermodiffraction. 
The aforementioned boranes are (white) solids in ambient conditions and are stable when kept under inert atmosphere. This has been an attractive feature for the foreseen application [1]. The solid-state is explained by the existence of intermolecular dihydrogen bonds $\mathrm{N}-\mathrm{H}^{\delta+} \ldots \mathrm{H}^{\delta-}-\mathrm{B}$ between the protic and hydridic hydrogen atoms coexisting in the molecules [11]. For example, $\mathrm{AB}$ and $\mathrm{HBB}$ differ from, respectively, the isoelectronic ethane $\mathrm{CH}_{3} \mathrm{CH}_{3}$ and butane $\mathrm{CH}_{3} \mathrm{C}_{2} \mathrm{H}_{4} \mathrm{CH}_{3}$ in physical state, structure and dynamics in ambient conditions. Another consequence of the intermolecular dihydrogen bonds is that the materials are highly crystalline [12], allowing for extensive crystallographic studies like in situ synchrotron X-ray thermodiffraction.

The compounds $\mathrm{AB}$ and $\mathrm{HB}$ have also been shown to be efficient precursors for synthesis of derivatives, mainly by mechanosynthesis in the presence of an alkaline hydride $\mathrm{MH}$ with $\mathrm{M}$ as $\mathrm{Li}, \mathrm{Na}$ or $\mathrm{K}$. Amidoboranes $\mathrm{MNH}_{2} \mathrm{BH}_{3}$ and hydrazinidoboranes $\mathrm{MN}_{2} \mathrm{H}_{3} \mathrm{BH}_{3}$ are synthesized respectively. For example, the polymorphic derivative lithium hydrazinidoborane ( $\mathrm{LiHB}$ ) is obtained by ball-milling $\mathrm{HB}$ and $\mathrm{LiH}$ in equimolar amounts, and depending on the milling conditions, two different phases can be obtained. The $\beta$ phase, $\beta$-LiHB, is orthorhombic with a space group $\mathrm{Pbca}$ [13]. It is in fact the low-temperature phase. Under heating and especially at around $90{ }^{\circ} \mathrm{C}$, it transforms into the high-temperature phase $\alpha$-LiHB crystallizing in a monoclinic structure with a $P 2_{1} / c$ unit cell [14]. Otherwise, the latter phase can be directly synthesized by milling in adequate conditions [15]. The potential of these amidoborane and hydrazinidoborane derivatives for solid-state chemical hydrogen storage was successfully assessed. They showed much better dehydrogenation properties than the parent boranes in terms of onset temperature of dehydrogenation and purity of hydrogen $[4,16]$. Hydrazinidoboranes are also (white) crystalline solids and can be effectively analyzed by X-ray thermodiffraction.

In the present work, six boranes were selected to be studied by in situ synchrotron X-ray thermodiffraction over a broad temperature range from 80 to $300 \mathrm{~K}$ (even $350 \mathrm{~K}$ for the most stable borane). On the one hand, $\mathrm{AB}, \mathrm{HB}$ and $\mathrm{HBB}$ (all in pristine state) were considered and the variations compared. $\mathrm{AB}$ was chosen as reference. On the other hand, two of the derivatives of $\mathrm{HB}$, i.e., $\mathrm{LiHB}$ (the $\alpha$ phase) and sodium hydrazinidoborane $(\mathrm{NaHB})$, were analyzed and the variations compared to those of HB. In addition, sodium triborane $\mathrm{NaB}_{3} \mathrm{H}_{8}$ (STB; also called sodium octahydrotriborate), another promising boron-based material for energy applications [17], was subjected to a similar study. The main objectives of the work were to scrutinize possible structural changes for the different boranes, to study the evolution of the unit cell dimensions, and to compare the boranes while analyzing the impact of the molecular structure on the crystallographic evolution. Our main results are reported and discussed hereafter.

\section{Results}

\subsection{Ammonia Borane $A B$}

The first borane to be investigated here is the well-known AB. It was considered as reference. Structural evolution over the temperature range 81-301 K was studied. The in situ X-ray diffraction patterns are presented in Figure 1. In our conditions, $A B$ undergoes a structural phase transition at around $205 \mathrm{~K}$ (Figure S1). Elsewhere it was suggested that this polymorphic transition is quite close to a second order, as follows from almost gradual evolution of the cell dimensions [19]. The transition temperature of $205 \mathrm{~K}$ in our conditions is lower by $15-20 \mathrm{~K}$ of that reported in previous works $[12,18,19]$. This may be related to the nature and synthesis procedure of the borane: ours was lab-prepared and it was of high purity $(>99 \%)$, whereas those in references $[12,18,19]$ were commercial and with lower purity. The transition occurs between the low-temperature orthorhombic phase (s.g. Pmn2 ${ }_{1}$, Figure S2) to the high-temperature tetragonal phase (s.g. $14 \mathrm{~mm}$, Figure S3). The transition is characterized by first-order rotational order-disorder associated to substantial increase of the entropy [20]. 


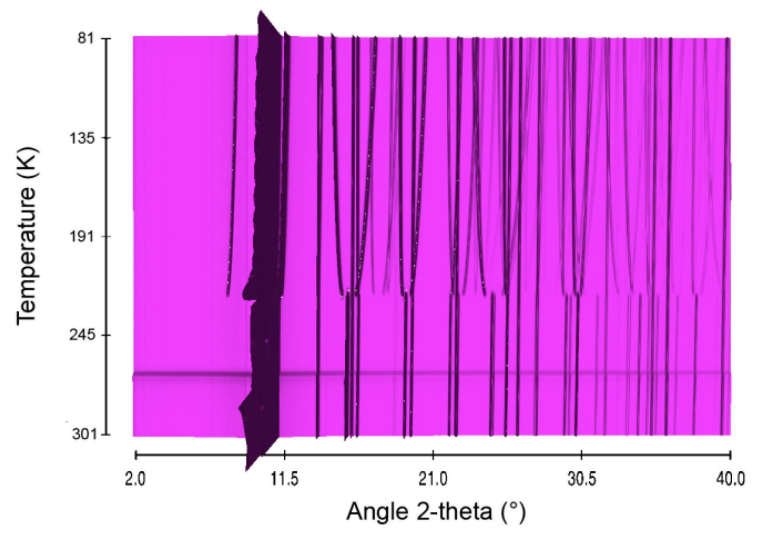

Figure 1. Sequential plot of the diffraction patterns of $A B$ within the range of temperature $81-301 \mathrm{~K}$.

The cell dimensions (Figure 2 and Table 1) are also consistent with previous reports [12,18,19]. The orthorhombic phase shows a negative coefficient of thermal expansion for $a$, and a positive coefficient for both $b$; the $c$ cell dimension remains virtually unchanged. With respect to the tetragonal phase, the variations of the unit cell parameters are quasi-linear. They all exhibit positive coefficients of thermal expansion.

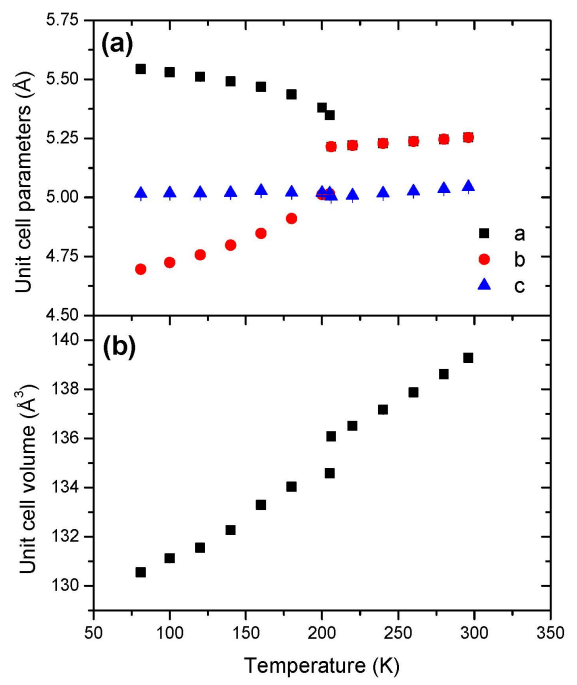

Figure 2. Temperature dependence of (a) the unit cell parameters and (b) the unit cell volume of $\mathrm{AB}$ within the range of temperature $81-301 \mathrm{~K}$.

Table 1. Crystal phase, space group (s.g.), temperature $T(\mathrm{~K})$ at which the structure was determined, formula unit $Z$ and unit cell parameters of the boranes.

\begin{tabular}{cccccccccc}
\hline Borane & Phase & s.g. & $\mathbf{T ~ ( K )}$ & $\mathbf{Z}$ & $\mathbf{a}(\AA)$ & $\mathbf{b}(\AA)$ & $\mathbf{c}(\AA)$ & $\beta\left({ }^{\circ}\right)$ & $\mathbf{V}(\AA)$ \\
\hline \multirow{2}{*}{$\mathrm{AB}$} & Orthorhombic & $P m n 2_{1}$ & 81 & 2 & $5.5437(2)$ & $4.6958(2)$ & $5.0190(2)$ & $130.5(1)$ \\
& Tetragonal & $I 4 m m$ & 296 & 2 & $5.2545(2)$ & & $5.0444(1)$ & $139.3(1)$ \\
\hline \multirow{2}{*}{$\mathrm{HB}$} & Orthorhombic & $P b c n$ & 101 & 8 & $12.9604(2)$ & $5.0632(2)$ & $9.4917(2)$ & $622.8(1)$ \\
\hline \multirow{2}{*}{$\mathrm{HBB}$} & Orthorhombic & $P b c a$ & 81 & 4 & $7.2654(4)$ & $7.3505(4)$ & $8.1109(5)$ & $433.2(1)$ \\
& Orthorhombic & $P b c a$ & 296 & 4 & $7.6491(8)$ & $7.6909(9)$ & $7.6728(1)$ & $451.4(1)$ \\
\hline \multirow{2}{*}{$\mathrm{LiHB}$} & Monoclinic & $P 2_{1} / c$ & 81 & 4 & $5.8528(3)$ & $7.4060(4)$ & $8.8450(5)$ & $122.65(1)$ & $322.8(2)$ \\
\hline \multirow{2}{*}{ NaHB } & Monoclinic & $P 2_{1} / n$ & 81 & 4 & $9.2306(3)$ & $7.8976(2)$ & $4.9648(2)$ & $93.64(2)$ & $361.2(1)$ \\
\hline STB & Orthorhombic & $P m n 2_{1}$ & 82 & 2 & $7.7934(2)$ & $5.8174(2)$ & $4.5389(1)$ & & $208.8(1)$ \\
\hline
\end{tabular}


The unit cell volume of $\mathrm{AB}$ increases with temperature. The evolution is non-linear for the orthorhombic phase (Figure S4). However, unlike in reference [19], the unit cell volume of the tetragonal phase displays a non-linear variation (Figure S5). In our conditions, both phases show thus anisotropic cell expansion. The $P m n 2_{1}$-to-I $1 \mathrm{~mm}$ transition is characterized by a unit cell volume increase by $1.1 \%$, which is higher than the values $0.27 \%$ and $0.33 \%$ reported elsewhere [12,19].

The thermal equations of state (Table 2) provide $V_{0}$ parameters (defined at $298 \mathrm{~K}$ ) of 142.6 and $139.35 \AA^{3}$ for the orthorhombic and tetragonal phases. Furthermore, the coefficient of thermal expansion $\alpha_{0}$ of the orthorhombic phase is twice as large as that of the other phase, with $63.93 \times 10^{-5} \mathrm{~K}^{-1}$ vs. $29.65 \times 10^{-5} \mathrm{~K}^{-1}$. The cell expansion of the orthorhombic phase is thus much more sensitive to the temperature variation.

Table 2. Parameters $\left(V_{0}, \alpha_{0}\right.$ and $\left.\alpha_{1}\right)$ of the thermal equations of state obtained for the boranes, with $T(\mathrm{~K})$ as the temperature of transition.

\begin{tabular}{cccccc}
\hline Borane & Phase & $\mathbf{T}(\mathbf{K})$ & $\mathbf{V}_{\mathbf{0}}(\AA \AA)$ at $\mathbf{2 9 8} \mathbf{K}$ & $\alpha_{\mathbf{0}}\left(\times \mathbf{1 0}^{-5} \mathbf{K}^{-1}\right)$ & $\alpha_{\mathbf{1}}\left(\times \mathbf{1 0}^{-8} \mathbf{K}^{-2}\right)$ \\
\hline \multirow{2}{*}{$\mathrm{AB}$} & Orthorhombic & $<205$ & $142.60(1)$ & $63.93(1)$ & $231.89(1)$ \\
& Tetragonal & $>205$ & $139.35(1)$ & $29.65(1)$ & $92.28(1)$ \\
\hline \multirow{2}{*}{$\mathrm{HB}$} & Orthorhombic & $<240$ & $641.84(1)$ & $3.96(1)$ & $-111.52(1)$ \\
& Orthorhombic & $>240$ & $640.25(1)$ & $20.71(1)$ & $178.58(1)$ \\
\hline \multirow{2}{*}{$\mathrm{HBB}$} & Orthorhombic & $<288$ & $447.45(1)$ & $18.71(1)$ & $33.96(1)$ \\
& Orthorhombic & $>288$ & $451.12(1)$ & $8.53(1)$ & $270.95(1)$ \\
\hline \multirow{2}{*}{ LiHB } & Monoclinic & & $327.86(1)$ & $10.57(1)$ & $32.08(1)$ \\
\hline \multirow{2}{*}{ NaHB } & Monoclinic & & $368.43(1)$ & $10.31(1)$ & $20.03(1)$ \\
\hline \multirow{2}{*}{ STB } & Orthorhombic & & $218.55(1)$ & $43.95(1)$ & $160.61(1)$ \\
\hline
\end{tabular}

\subsection{Hydrazine Borane $H B$}

Structural evolution of HB was then studied over the temperature range 101-295 K. The in situ $X$-ray diffraction patterns are presented in Figure 3. The thermal behavior of $\mathrm{HB}$ is different from that of $\mathrm{AB}$. With $\mathrm{HB}$, there is no phase transition. The patterns were indexed in the orthorhombic phase with a Pbcn unit cell (Figure S6).

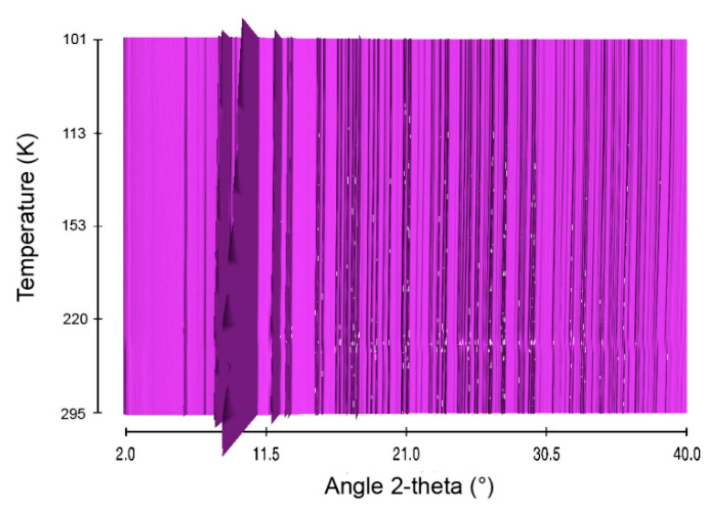

Figure 3. Sequential plot of the diffraction patterns of HB within the range of temperature 101-295 K.

The cell dimensions $(a, b, c)$ were determined from the Le Bail refinement (Figure 4). The unit cell parameters refined at $101 \mathrm{~K}$ reported in Table 1 are consistent with previous reports $[7,9,15]$. Over the whole range of temperature $101-314 \mathrm{~K}$, the parameters $a, b$ and $c$ exhibit a positive coefficient of thermal expansion.

The unit cell volume presents two domains, but HB still has an orthorhombic structure (s.g. Pbcn) over the whole temperature range. At $240 \mathrm{~K}$, the unit cell volume decreases by $0.85 \%$. Furthermore, 
the coefficient of thermal expansion undergoes a substantial increase, by a factor of 5 , with $\alpha_{0}$ values of $3.96 \times 10^{-5} \mathrm{~K}^{-1}$ vs. $20.71 \times 10^{-5} \mathrm{~K}^{-1}$ (Table 2). The high-temperature form is thus more temperature-sensitive, which can be explained by a loss of order (higher disorder) and an enhanced molecular agitation. Over the ranges 101-240 and 240-314 K, the evolutions of the unit cell volume are non-linear (Figures S7 and S8), indicating anisotropic cell expansion.

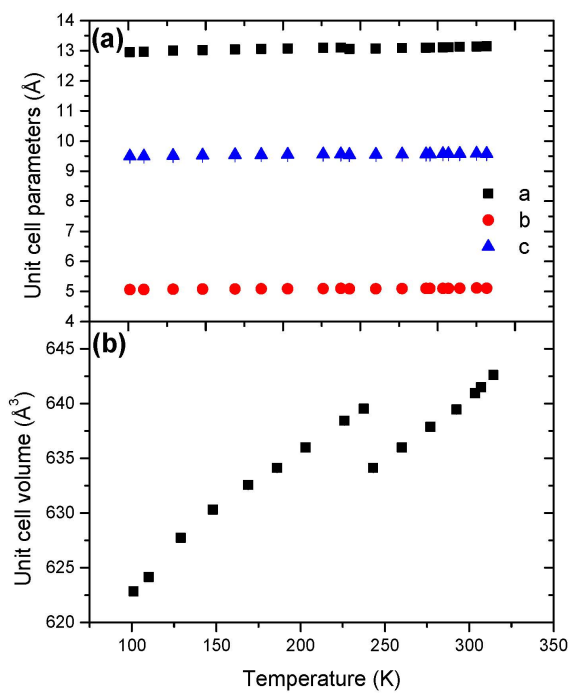

Figure 4. Temperature dependence of (a) the unit cell parameters and (b) the unit cell volume for HB in the temperature range $101-314 \mathrm{~K}$.

\subsection{Hydrazine Bisborane $H B B$}

Structural evolution of HBB was actually studied in a previous work [10]. The X-ray diffraction patterns obtained over the temperature range 81-292 K (Figure 5, Figures S9 and S10 in supplementary) are adapted herein and further exploited for comparison. The thermal behavior of HBB is different from those of $\mathrm{AB}$ and $\mathrm{HB}$. At $288 \mathrm{~K}$, there is a structural transformation, which is reversible. It occurs between two orthorhombic structures, both having a Pbca unit cell. The transition takes place in a domain of temperature of about $10 \mathrm{~K}$ (Figure S11). Within this domain, both phases coexist.

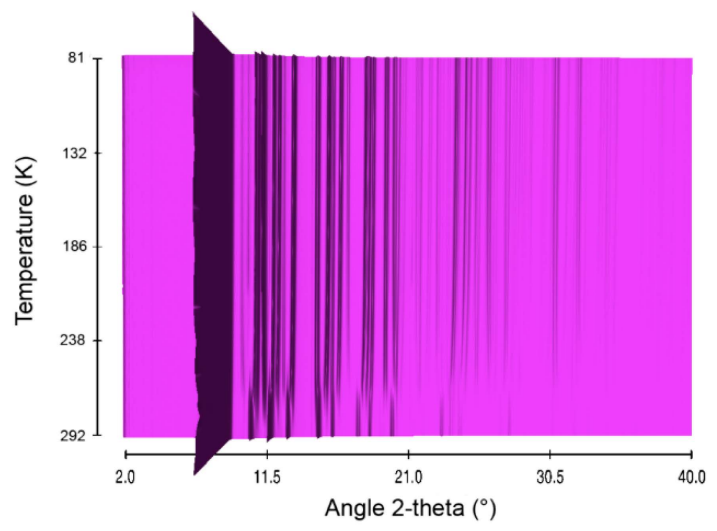

Figure 5. Sequential plot of the diffraction patterns of HBB within the range of temperature $81-292 \mathrm{~K}$.

With respect to the low-temperature phase, the parameters $a$ and $b$ show a positive coefficient of thermal expansion whereas the parameter $c$ decreases with the temperature increase (Figure 6). The behavior of the high-temperature phase strongly differs with a positive evolution for the three parameters. At the transition, $c$ abruptly decreases and concomitantly both $a$ and $b$ increase, all of the 
three parameters reaching similar values (7.6-7.7 $)$. The unit cell parameters refined at 81 and $296 \mathrm{~K}$ are reported in Table 1.

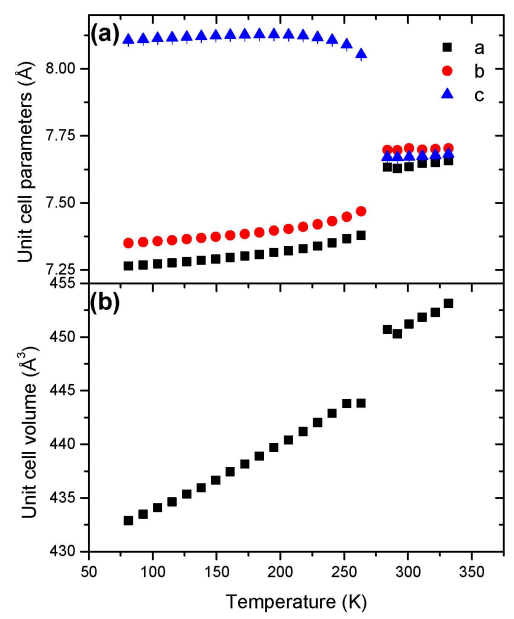

Figure 6. Temperature dependence of (a) the unit cell parameters and (b) the unit cell volume for HBB in the temperature range $81-332 \mathrm{~K}$.

The unit cell volume of both phases increase with temperature (Figures S12 and S13). The evolutions are not linear. This indicates anisotropic cell expansion. The coefficient of thermal expansions $\alpha_{0}$ were found to be in a ratio of about 2-to- 1 with $18.71 \times 10^{-5} \mathrm{~K}^{-1}$ and $8.53 \times 10^{-5} \mathrm{~K}^{-1}$ for the low-temperature and high-temperature forms respectively (Table 2). At $298 \mathrm{~K}$, the parameter $V_{0}$ of the latter phase is higher by $0.8 \%$ (Table 2). Disorder is accentuated at high temperature because of a higher degree of freedom of the molecules in the unit cell.

\subsection{Lithium Hydrazinidoborane LiHB}

Structural evolution of the lithium derivative of $\mathrm{HB}, \mathrm{LiHB}$, was also investigated (Figure 7). The patterns obtained for the temperature range 81-301 K were indexed in the monoclinic phase with the space group $P 2_{1} / c$ (Figure S14). The unit cell parameters (Table 1 ) are in good agreement with those reported elsewhere [13,15].

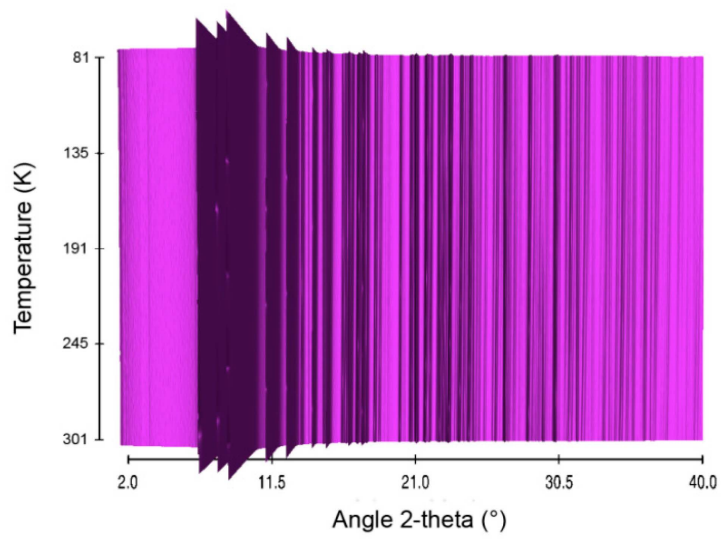

Figure 7. Sequential plot of the diffraction patterns of LiHB within the range of temperature $81-301 \mathrm{~K}$.

The unit cell parameter $c$ presents a negative coefficient of thermal expansion (Figure 8). With respect to $a$ and $b$, the coefficient is positive. The unit cell volume presents a non-linear evolution with a positive coefficient of thermal expansion (Figure S15), suggesting anisotropic expansion. The coefficient of thermal expansion was found to be $10.57 \times 10^{-5} \mathrm{~K}^{-1}$ (Table 2). 


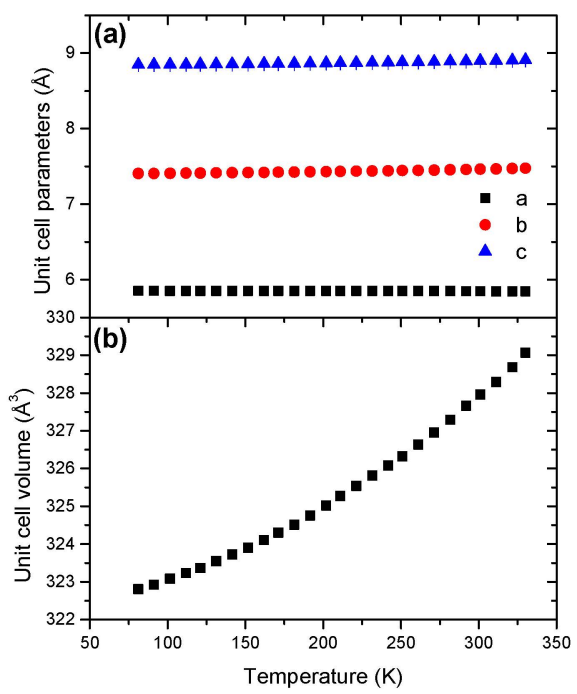

Figure 8. Temperature dependence of (a) the unit cell parameters and (b) the unit cell volume for LiHB in the temperature range $81-330 \mathrm{~K}$.

\subsection{Sodium Hydrazinidoborane $\mathrm{NaHB}$}

The second derivative of $\mathrm{HB}$ is $\mathrm{NaHB}$. It forms by reaction of $\mathrm{NaH}$ and $\mathrm{HB}$ at $235 \mathrm{~K}$, and it is structurally stable up to $293 \mathrm{~K}$ [14]. Herein, it was also found to be stable in the range of temperature from 81 to $287 \mathrm{~K}$ (Figure 9). No temperature-induced phase transition was noticed. The diffraction patterns were successfully indexed in the monoclinic phase with the space group $P 21 / n$ (Figure S16). The unit cell parameters extracted at $81 \mathrm{~K}$ are reported in Table 1, and are in agreement with the literature [21].

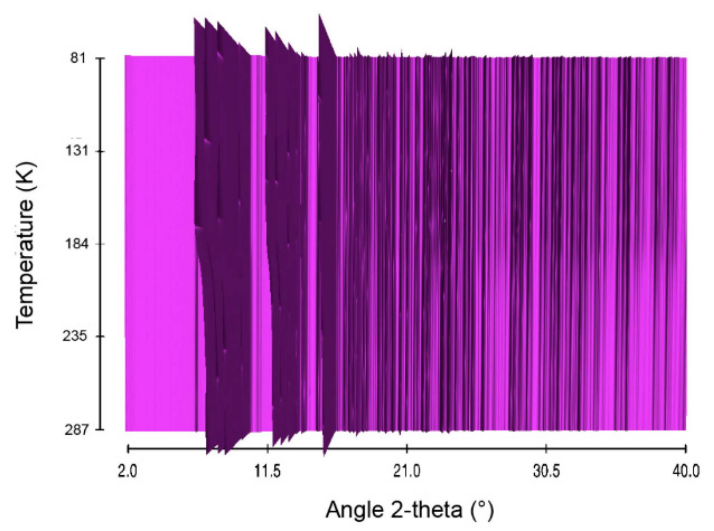

Figure 9. Sequential plot of the diffraction patterns of NaHB within the range of temperature $81-287 \mathrm{~K}$.

Like for LiHB, the unit cell parameters of NaHB exhibit a positive evolution (Figure 10) and the unit cell volume presents a normal evolution with positive coefficient of thermal expansion (Figure S17). The unit cell volume variation is not linear, which is consistent with an anisotropic expansion.

The coefficient of thermal expansion was found to be $10.31 \times 10^{-5} \mathrm{~K}^{-1}$ (Table 2), which is similar to the coefficient found for LiHB. 


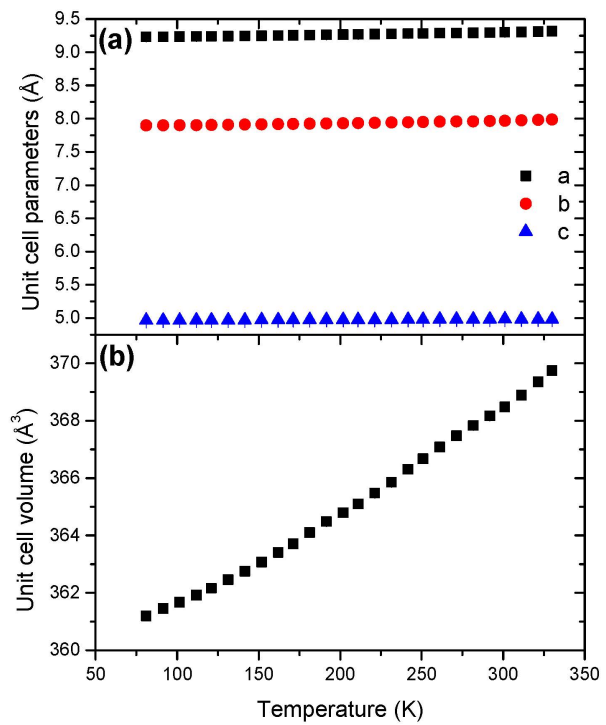

Figure 10. Temperature dependence of (a) the unit cell parameters and (b) the unit cell volume for $\mathrm{NaHB}$ in the temperature range $81-328 \mathrm{~K}$.

\subsection{Sodium Triborane STB}

The last compound studied herein was STB. Structural evolution was investigated over the range 81-301 K (Figure 11). No phase transition was detected. The diffraction patterns were indexed in the orthorhombic phase with the non-centrosymmetric space group Pmn2 (Figure S18). The unit cell parameters extracted at $82 \mathrm{~K}$ are reported in Table 1. The results on STB are in fact in agreement with the literature [22].

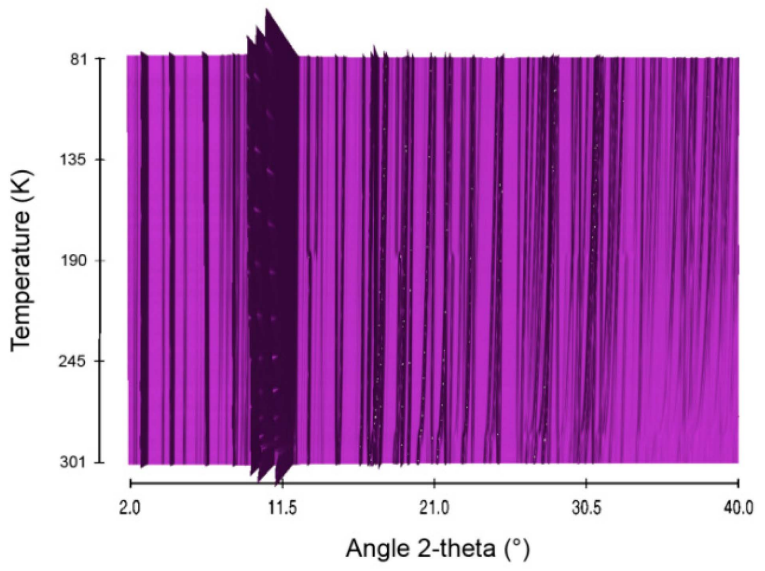

Figure 11. Sequential plot of the diffraction patterns of STB within the range of temperature $81-301 \mathrm{~K}$.

The evolutions of the unit cell parameters and of the unit cell volume are shown in Figure 12. The parameter $b$ decreases with the temperature increase whereas the parameters $a$ and $c$ increase. The unit cell volume increases as a function of the temperature (Figure S19), with a coefficient of thermal expansion of $43.95 \times 10^{-5} \mathrm{~K}^{-1}$ (Table 2). This is the second highest coefficient when compared to the other boranes. The unit cell volume increase is not linear and the cell expansion is thus anisotropic. 


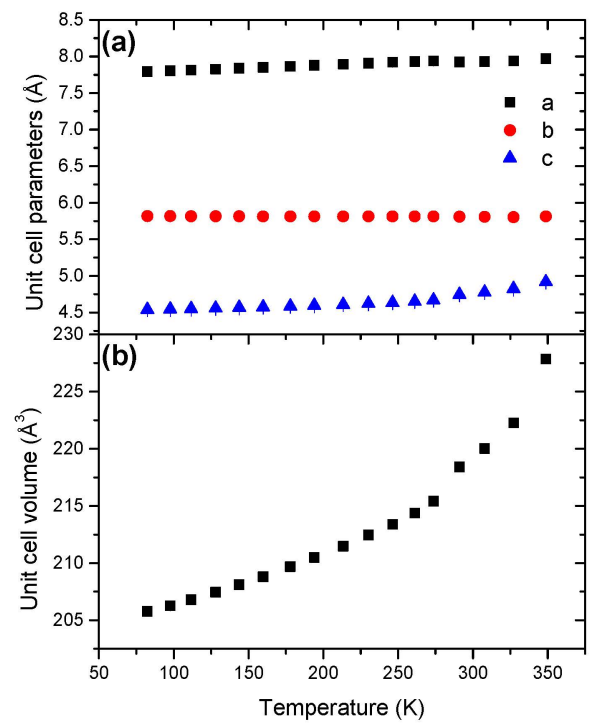

Figure 12. Temperature dependence of (a) the unit cell parameters and (b) the unit cell volume for STB in the temperature range $81-349 \mathrm{~K}$.

\section{Discussion}

The replacement of the $\mathrm{NH}_{3}$ moiety of $\mathrm{AB}$ by $\mathrm{N}_{2} \mathrm{H}_{4}$ leads to $\mathrm{HB}$, and the addition of a $\mathrm{BH}_{3}$ group to HB leads to HBB. This is accompanied by an increase of the molecular weight $(30.8,45.8$, $59.6 \mathrm{~g} \cdot \mathrm{mol}^{-1}$ respectively) and thus of the molecules size. Accordingly, one molecule of $\mathrm{AB}$, one of HB and one of HBB occupy a volume of about 65,78 and $108 \AA^{3}$ in the low-temperature cell (Tables 1 and 2).

At low temperature, $\mathrm{AB}, \mathrm{HB}$ and $\mathrm{HBB}$ all crystallizes in the orthorhombic structure but with different space groups; it is the non-centrosymmetric $P m n 2_{1}$ for $\mathrm{AB}$, and the centrosymmetric $\mathrm{Pbcn}$ and $\mathrm{Pbca}$ for $\mathrm{HB}$ and HBB respectively. In the unit cell, the $c$ axis and the B-N bonds are secant with a tilt angle. For $A B$, the angle is $11.8^{\circ}$ for the unit cell at $81 \mathrm{~K}$. Slightly higher angles such as $17.4^{\circ}$ and $19.3^{\circ}$ were found for $\mathrm{HB}$ and $\mathrm{HBB}$ respectively.

The increase of the temperature implies disorder (as suggested by the anisotropic cell expansions). $\mathrm{AB}$ is more sensitive to temperature change than the other boranes, as evidenced by the coefficient of thermal expansion of $63.93 \times 10^{-5} \mathrm{~K}^{-1}$ (Table 2). In fact, with $\mathrm{AB}$, disordering is accompanied by a transition (at $205 \mathrm{~K}$ ) into a tetragonal phase (s.g. $14 \mathrm{~mm}$ ) with twelvefold or higher-order reorientation of the $\mathrm{BH}_{3}$ and $\mathrm{NH}_{3}$ groups [12]. In this high-temperature phase, the $\mathrm{B}-\mathrm{N}$ bonds are aligned along the $c$ axis of the unit cell [20]. At $204 \mathrm{~K}$, just before the transition, the aforementioned tilt angle decreases to $5.3^{\circ}$, confirming the cell expansion and the temperature-induced motion of the $\mathrm{AB}$ molecules.

With $\mathrm{HB}$, there is no change in the crystal structure. It is less temperature-sensitive than $A B$. However, the unit cell abruptly changes at $240 \mathrm{~K}$ such that the volume decreases by $0.85 \%$. For the unit cell at $294 \mathrm{~K}$, a tilt angle of $18.5^{\circ}$ is found. It is $1.1^{\circ}$ higher than that found at $101 \mathrm{~K}$. Such an evolution may induce a cell contraction, rationalizing the abrupt decrease of the unit cell volume occurring at $240 \mathrm{~K}$.

With HBB, there is no change in the crystal structure but the cell unit parameters significantly change and the unit cell volume increases by $0.8 \%$ at $288 \mathrm{~K}$. This is also accompanied by a significant change in the tilt angle between the $c$ axis and the B-N bond since it is equal to $31^{\circ}$ at $294 \mathrm{~K}$. Temperature-induced disorder leads to a new reorganization of the four HBB molecules in the unit cell, without impacting the crystal structure.

The above-discussed differences may be explained by the molecular size as well as the molecular conformation of the boranes. The molecules of $\mathrm{AB}$ are eclipsed and the motions of $\mathrm{BH}_{3}$ and $\mathrm{NH}_{3}$ groups are independent [23]. The molecules of $\mathrm{HB}$ are bent with a BNN angle of $118.8^{\circ}$ at $101 \mathrm{~K}$, 
which limits the motion of the $\mathrm{N}_{2} \mathrm{H}_{4}$ group by the presence of adjacent molecules. HBB has chair conformation, with a BNN angle of $114.1^{\circ}$ at $81 \mathrm{~K}$, which increases to $136^{\circ}$ at $294 \mathrm{~K}$.

The substitution of the protic hydrogen $\mathrm{H}^{\delta+}$ of the central $\mathrm{NH}_{2}$ group of the molecule of $\mathrm{HB}$ by $\mathrm{Li}^{+}$leads to $\mathrm{LiHB}$ where the alkali cation is tetracoordinated with four $\left[\mathrm{NH}_{2} \mathrm{NHBH}_{3}\right]^{-}$entities $[4,15]$. With $\mathrm{NaHB}$, the sodium cation is surrounded by five symmetry-equivalent anions $[4,21]$. The bigger size of $\mathrm{Na}^{+}$(116 pm vs. $90 \mathrm{pm}$ for $\mathrm{Li}^{+}$) explains its higher coordination degree and the bigger unit cell volume of $\mathrm{NaHB}$. Consequently, the volume occupied by one of these molecules in the unit cell increases from $\mathrm{HB}$ to $\mathrm{NaHB}$, via LiHB (Tables 1 and 2).

The presence of the alkali cation has also a stabilizing effect on the unit cell. Unlike with HB, no abrupt change due phase transition or cell contraction/expansion was noticed. Anisotropic cell expansion was observed only. Furthermore, the coefficients of thermal expansion were found similar for both $\mathrm{LiHB}$ and $\mathrm{NaHB}$, suggesting similar disorder-related behavior under heating. This may be explained by a stabilizing effect of the tetra- and penta-coordination abilities of $\mathrm{Li}^{+}$and $\mathrm{Na}^{+}$with four and five $\left[\mathrm{NH}_{2} \mathrm{NHBH}_{3}\right]^{-}$anions respectively.

The crystal structure of STB is similar to that of $\mathrm{AB}$ (orthorhombic, s.g. Pmn2 1 ). STB is a bigger molecule (molecular weight of $63.4 \mathrm{~g} \cdot \mathrm{mol}^{-1}$ ) and occupy more volume in the unit cell (104 vs. $65 \AA^{3}$ ). Like for $\mathrm{LiHB}$ and $\mathrm{NaHB}$, each $\mathrm{Na}^{+}$of STB is surrounded by several $\mathrm{B}_{3} \mathrm{H}_{8}{ }^{-}$anions, typically four, and is coordinated through six $\mathrm{Na} \cdots \mathrm{H}$ interactions [22]. STB is much sensitive to the temperature increase, as evidenced by a coefficient of thermal expansion of $43.95 \times 10^{-5} \mathrm{~K}^{-1}$. In one respect, STB has a structural evolution between that of $\mathrm{AB}$ and that of NaHB.

\section{Experimental Section}

Synthesis of $\mathrm{AB}, \mathrm{HB}, \mathrm{HBB}, \mathrm{LiHB}, \mathrm{NaHB}$, and $\mathrm{STB}$ were carried out according to procedures reported in details elsewhere $[9,10,15,21,24,25]$. After synthesis, the samples were stored in an argon-filled glove box (MBraun M200B, $\mathrm{O}_{2}<0.1 \mathrm{ppm}, \mathrm{H}_{2} \mathrm{O}<0.1 \mathrm{ppm}$ ).

The thermal behavior of the aforementioned boranes was investigated by $\mathrm{X}$-ray thermodiffractometry using synchrotron radiation. All of the experiments were performed on the Swiss Norwegian Beam Line (SNBL, BM01A) at European Synchrotron Facility (Grenoble, France). The diffraction patterns were collected using a monochromatic beam and PILATUS 2M detector. The sample-detector distance $(343.71 \mathrm{~mm})$, the parameters of the detector and the wavelength of $0.70814 \AA$ were calibrated using NIST standard $\mathrm{LaB}_{6}$. The temperature was controlled with an Oxford Cryostream 700+ allowing working over a wide range of temperature 80-350 K.

For the in situ X-ray diffraction experiments, the samples in powder form were loaded into glass capillaries of $0.5 \mathrm{~mm}$ diameter into an argon-filled glove box (MBraun Unilab fitted with a recirculation system and gas/humidity sensors; $\mathrm{O}_{2}<0.1 \mathrm{ppm}, \mathrm{H}_{2} \mathrm{O}<0.1 \mathrm{ppm}$ ). The capillaries were sealed before experiments to keep the loaded samples out of air and water. Prior to the experiments, the boranes were cooled down from room temperature to $80 \mathrm{~K}$ and then heated up at $60 \mathrm{~K}$ per hour $\left(1 \mathrm{~K} \cdot \mathrm{min}^{-1}\right.$ ) rate up to $300 \mathrm{~K}$ (even $350 \mathrm{~K}$ for the most stable borane, STB). Such a rate allowed fine temperature sampling [19]. The diffraction patterns were recorded simultaneously using a collection time of 60 images per hour $\left(1 \mathrm{image} \cdot \mathrm{min}^{-1}\right)$ and a rotation of the capillary of $60^{\circ}$. To get the patterns, the two-dimensional diffraction images were integrated using Fit2D software [26].

The fine temperature sampling allowed the determination of the cell dimensions $(a, b, c)$ from the Le Bail refinement. The unit cell parameters were refined using the Jana2006 software package [27] after having been indexed using DICVOL06 [28]. For each borane, a Rietveld refinement of the structure was also carried out using the Jana2006 software package to determine the tilt angle between the B-N bond and the $c$ axis as well as the BNN angle. The thermal equations of state were established using EosFit7 [29] and the Berman model [30]. The temperature of reference was taken to be equal to $298 \mathrm{~K}$ for the boranes without temperature-induced phase transition. It was the temperature of transition for the other ones. The unit cell volume and the fitted equation of state were systematically plotted as 
a function of the temperature. The parameter of the thermal equation of state and the coefficients of thermal expansion were thus obtained.

\section{Conclusions}

Six boranes of low molecular weight $(\mathrm{AB}, \mathrm{HB}, \mathrm{HBB}, \mathrm{LiHB}, \mathrm{NaHB}$ and $\mathrm{STB})$ have been investigated by in situ synchrotron X-ray thermodiffraction from 80 to $300 \mathrm{~K}$. First, AB, HB and HBB have been compared. They behave differently under heating depending on the molecular size, the conformation and motion (degree of freedom) of the chemical groups $\left(\mathrm{NH}_{3}, \mathrm{~N}_{2} \mathrm{H}_{4}, \mathrm{BH}_{3}\right)$.

- $\mathrm{AB}$ is highly temperature-sensitive in comparison to $\mathrm{HB}$ and $\mathrm{HBB}$, and a Pmn $2_{1}$-to-I4mm phase transition takes place at $205 \mathrm{~K}$.

- $\quad \mathrm{HB}$ has an orthorhombic structure (s.g. $\mathrm{Pbcn}$ ) over the whole temperature range but the unit cell volume decreases by $0.85 \%$. This is explained by an increase of the tilt angle between the $c$ axis and the B-N bond and a subsequent cell contraction.

- $\quad \mathrm{HBB}$ has an orthorhombic structure (s.g. Pbca) but the unit cell significantly changes at $288 \mathrm{~K}$. For example, the tilt angle is $114.1^{\circ}$ at $81 \mathrm{~K}$ whereas it is $136^{\circ}$ at $294 \mathrm{~K}$. Temperature-induced disorder leads to a new reorganization of the four HBB molecules in the unit cell, without impacting the crystal structure.

Second, the alkali boranes LiHB, NaHB and STB have been studied, and the data compared to those of the previous boranes.

- For all of them, the cell expansion is anisotropic and there is no transition over the whole temperature range.

- $\quad$ LiHB and NaHB behave differently from the parent borane HB. Furthermore, the coefficients of thermal expansions are similar for LiHB and NaHB, suggesting similar disorder-related behavior under heating. This is explained by the presence of the alkali cations that would have stabilizing effect on the unit cell via $\mathrm{M} \cdots \mathrm{H}$ interactions with four to five borane anions.

STB is highly temperature-sensitive and in one respect has a structural evolution between that of $\mathrm{AB}$ and that of NaHB.

Supplementary Materials: Supplementary materials can be accessed at http://www.mdpi.com/2073-4352/ $6 / 2 / 16 / \mathrm{s} 1$.

Acknowledgments: The authors thank the European Synchrotron Radiation Facility (ESRF) and the Swiss Norvegian Beam Line (SNBL, BM01A) for the beam time allocation. We also thank Dmitry Chernysov (ESRF SNBL), Fabrice Salles (ICGM) and Jean-Fabien Petit (IEM) for technical assistance during the X-ray experiments.

Author Contributions: U.B.D. synthesized the samples, prepared the capillaries, determined some of the cell parameters, and managed the manuscript writing. P.G.Y. did the XRD experiments, determined the cell parameters for most of the samples, refined the molecular structures and contributed to the manuscript preparation. P.M. contributed to the manuscript preparation.

Conflicts of Interest: The authors declare no conflict of interest.

\section{References}

1. Jepsen, L.H.; Ley, M.B.; Lee, Y.S.; Cho, Y.W.; Dornheim, M.; Jensen, J.O.; Filinchuk, Y.; Jørgensen, J.E.; Besenbacher, F.; Jensen, T.R. Boron-Nitrogen Based Hydrides and Reactive Composites for Hydrogen Storage. Mater. Today 2014, 17, 129-135. [CrossRef]

2. Li, H.W.; Yan, Y.; Orimo, S.I.; Züttel, A.; Jensen, C.M. Recent Progress in Metal Borohydrides for Hydrogen Storage. Energies 2011, 4, 185-214. [CrossRef]

3. Huang, Z.; Autrey, T. Boron-Nitrogen-Hydrogen (BNH) Compounds: Recent Developments in Hydrogen Storage, Applications in Hydrogenation and Catalysis, and New Syntheses. Energy Environ. Sci. 2012, 5, 9257-9268. [CrossRef]

4. Moury, R.; Demirci, U.B. Hydrazine Borane and Hydrazinidoboranes as Chemical Hydrogen Storage Materials. Energies 2015, 8, 3118-3141. [CrossRef] 
5. Parry, R.W.; Schultz, D.R.; Girardot, P.R. The preparation and properties of hexaaminecobalt(III) borohydride, hexaamminechromium(III) borohydride and ammonium borohydride. J. Am. Chem. Soc. 1958, 80, 1-3. [CrossRef]

6. Shore, S.G.; Parry, R.W. The crystalline compound ammonia-borane, $\mathrm{H}_{3} \mathrm{NBH}_{3}$. J. Am. Chem. Soc. 1955, 77, 6084-6085. [CrossRef]

7. Goubeau, J.; Ricker, E. Borinhydrazin und seine Pyrolyseprodukte. Z. Anorg. Allg. Chem. 1961, 310, $123-142$. [CrossRef]

8. Emeléus, H.J.; Stone, F.G.A. The Reaction between Diborane and Anhydrous Hydrazine. J. Chem. Soc. 1951, 840-841.

9. Moury, R.; Moussa, G.; Demirci, U.B.; Hannauer, J.; Bernard, S.; Petit, E.; van der Lee, A.; Miele, P. Hydrazine Borane: Synthesis, Characterization, and Application Prospects in Chemical Hydrogen Storage. Phys. Chem. Chem. Phys. 2012, 14, 1768-1777. [CrossRef] [PubMed]

10. Pylypko, S.; Petit, E.; Yot, P.G.; Salles, F.; Cretin, M.; Miele, P.; Demirci, U.B. Key Study of the Potential of Hydrazine Bisborane for Solid- and Liquid-State Chemical Hydrogen Storage. Inorg. Chem. 2015, 54, 4574-4583. [CrossRef] [PubMed]

11. Richarson, T.B.; de Gala, S.; Crabtree, R.H. Unconventional Hydrogen Bonds: Intermolecular B-H ‥ H-N Interactions. J. Am. Chem. Soc. 1995, 117, 12875-12876. [CrossRef]

12. Hoon, C.F.; Reynhardt, E.C. Molecular Dynamics and Structures of Amine Boranes of the Type $\mathrm{R}_{3}$ N.BH. $\mathrm{I}$. X-ray Investigation $\mathrm{H}_{3} \mathrm{~N}_{\mathrm{BH}}$ at $295 \mathrm{~K}$ and $110 \mathrm{~K}$. J. Phys. C Solid State Phys. 1983, 16, 6129-6136. [CrossRef]

13. Moury, R.; Demirci, U.B.; Ban, V.; Filinchuk, Y.; Ichikawa, T.; Zeng, L.; Goshome, K.; Miele, P. Lithium Hydrazinidoborane: A Polymorphic Material with Potential for Chemical Hydrogen Storage. Chem. Mater. 2014, 26, 3249-3255. [CrossRef]

14. Moury, R.; Robeyns, K.; Filinchuk, Y.; Miele, P.; Demirci, U.B. In situ thermodiffraction to monitor synthesis and thermolysis of hydrazine borane-based materials. J. Alloy. Compd. 2016, 659, 210-216. [CrossRef]

15. Wu, H.; Zhou, W.; Pinkerton, F.E.; Udovic, T.J.; Yildirim, T.; Rush, J.J. Metal Hydrazinoborane $\mathrm{LiN}_{2} \mathrm{H}_{3} \mathrm{BH}_{3}$ and $\mathrm{LiN}_{2} \mathrm{H}_{3} \mathrm{BH}_{3} \cdot 2 \mathrm{~N}_{2} \mathrm{H}_{4} \mathrm{BH}_{3}$ : Crystal Structures and High-Extent Dehydrogenation. Energy Environ. Sci. 2012, 5, 7531-7535. [CrossRef]

16. Chua, Y.S.; Chen, P.; Wu, G.; Xiong, Z. Development of Amidoboranes for Hydrogen Storage. Chem. Commun. 2011, 47, 5116-5129. [CrossRef] [PubMed]

17. Huang, Z.; Chen, X.; Yisgedu, T.; Zhao, J.C.; Shore, S.G. High-Capacity Hydrogen Release through Hydrolysis of $\mathrm{NaB}_{3} \mathrm{H}_{8}$. Int. J. Hydrog. Energy 2011, 36, 7038-7042. [CrossRef]

18. Yang, J.B.; Lamsal, J.; Cai, Q.; James, W.J.; Yelon, W.B. Structural Evolution of Ammonia Borane for Hydrogen Storage. Appl. Phys. Lett. 2008, 92, 091916. [CrossRef]

19. Filinchuk, Y.; Nevidomskyy, A.H.; Chernyshov, D.; Dmitriev, V. High-Pressure and Transition Phenomena in Ammonia Borane $\mathrm{NH}_{3} \mathrm{BH}_{3}$ from X-Ray Diffraction, Landau Theory, and Ab Initio Calculations. Phys. Rev. B 2009, 79, 1-11. [CrossRef]

20. Reynhardt, E.C.; Hoon, C.F. Molecular Dynamics and Structures of Amine Branes of the Type $\mathrm{R}_{3}$ N.BH 3. II. NMR Investigation of $\mathrm{H}_{3} \mathrm{~N} \cdot \mathrm{BH}_{3}$. J. Phys. C Solid State Phys. 1983, 16, 6137-6152. [CrossRef]

21. Moury, R.; Demirci, U.B.; Ichikawa, T.; Chiriac, R.; van der Lee, A.; Miele, P. Sodium Hydrazinidoborane: A Chemical Hydrogen-Storage Material. Chem. Sustain. Chem. 2013, 6, 667-673. [CrossRef] [PubMed]

22. Dunbar, A.C.; Macor, J.A.; Girolami, G.S. Synthesis and Single Crystal Structure of Sodium Octahydrotriborate, $\mathrm{NaB}_{3} \mathrm{H}_{8}$. Inorg. Chem. 2014, 53, 822-826. [CrossRef] [PubMed]

23. Penner, G.H.; Chang, Y.C.P.; Hutzal, J. A Deuterium NMR Spectroscopic Study of Solid $\mathrm{BH}_{3} \mathrm{NH}_{3}$. Inorg. Chem. 1999, 38, 2868-2873. [CrossRef] [PubMed]

24. Figen, A.K.; Pişkin, M.B.; Coşkuner, B.; Imamoğlu, V. Synthesis, Structural Characterization, and Hydrolysis of Ammonia Borane $\left(\mathrm{NH}_{3} \mathrm{BH}_{3}\right)$ as a Hydrogen Carrier. Int. J. Hydrog. Energy 2013, 38, 16215-16228. [CrossRef]

25. Pylypko, S.; Zadick, A.; Chatenet, M.; Miele, P.; Cretin, M.; Demirci, U.B. A Preliminary Study of Sodium Octahydrotriborate $\mathrm{NaB}_{3} \mathrm{H}_{8}$ as Potential Anodic Fuel of Direct Liquid Fuel Cell. J. Power Sources 2015, 286, 10-17. [CrossRef]

26. Hammersley, A.P.; Svensson, S.O.; Hanfland, M.; Fitch, A.N.; Häusermann, D. Two-Dimensional Detector Software: From Real Detector to Idealised Image of Two-Theta Scan. High Press. Res. 1996, 14, $235-248$. [CrossRef] 
27. Petricek, V.; Dusek, M.; Palatinus, L. Crystallographic Computing System JANA2006: General Features. Z. Krist. 2014, 229, 345-352.

28. Boultif, A.; Louer, D. Indexing of Powder Diffraction Patterns for Low-Symmetry Lattices by the Successive Dichotomy Method. J. Appl. Crystallogr. 1991, 24, 987-993. [CrossRef]

29. Angel, R.J.; Gonzalez-Platas, J.; Alvaro, M. EosFit7c and a Fortran Module (Library) for Equation of State Calculations. Z. Krist. 2014, 229, 405-419. [CrossRef]

30. Berman, R.G. Internally-Consistent Thermodynamic Data for Minerals in the System $\mathrm{Na}_{2} \mathrm{O}-\mathrm{K}_{2} \mathrm{O}-\mathrm{CaO}-$ $\mathrm{MgO}-\mathrm{FeO}-\mathrm{Fe}_{2} \mathrm{O}_{3}-\mathrm{Al}_{2} \mathrm{O}_{3}-\mathrm{SiO}_{2}-\mathrm{TiO}_{2}-\mathrm{H}_{2} \mathrm{O}-\mathrm{CO}_{2}$. J. Petrol. 1988, 29, 445-522. [CrossRef]

(C) 2016 by the authors; licensee MDPI, Basel, Switzerland. This article is an open access article distributed under the terms and conditions of the Creative Commons by Attribution (CC-BY) license (http://creativecommons.org/licenses/by/4.0/). 